\title{
Diálogos sobre a emancipação: o contemporâneo na perspectiva de Bauman, Santos e Giddens
}

\section{Dialogues on emancipation: the contemporary from the perspective of Bauman, Santos and Giddens}

\author{
Crístian Andrei Tisatto*
}

\begin{abstract}
Resumo: O presente estudo busca discutir o conceito de emancipação, sua legitimidade e seu significado na contemporaneidade. Ainda, procura refletir sobre os desafios, limites e as possibilidades que corroboram para a efetivação da emancipação ou não. Tal discussão emerge, tendo em vista a configuração social que se apresenta: uma sociedade dita pós-moderna ou decolonial - que apresenta o consumo e o capital como categorias relevantes para a compreensão da dinâmica e de seus efeitos nas relações humanas. O trabalho desenvolve-se a partir de três autores de referência, os quais tratam do conceito: Zygmunt Bauman, Boaventura de Souza Santos e Anthony Giddens, autores que contribuíram por meio da oferta de elementos que subsidiaram as discussões abordadas e a construção de outras alternativas - outros paradigmas para a construção de um outro mundo possível, capaz de compreender a dinâmica social de modo não dualista, mas na sua singularidade e complexidade.
\end{abstract}

Palavras-chave: Emancipação. Pós-Modernidade. Decolonial.

\begin{abstract}
The present study seeks to discuss the concept of emancipation, its legitimacy and its significance in contemporary times. Still, it seeks to reflect on the challenges, limits and possibilities that corroborate for the realization of emancipation or not. Such a discussion emerges, in view of the social configuration that presents itself: a society called postmodern or decolonial - which presents consumption and capital as relevant categories for understanding the dynamics and their effects on human relations. The work is developed from three reference authors, who deal with the concept: Zygmunt Bauman, Boaventura de Souza Santos and Anthony Giddens, authors who contributed by offering elements that supported the discussed
\end{abstract}

\footnotetext{
* Mestrando em Ciências Sociais (Bolsa CAPES/PROSUC) no Programa de Pós-Graduação em Ciências Sociais da Universidade do Vale do Rio dos Sinos. Especialista em Gestão Escolar e Metodologia do Ensino de Filosofia e Sociologia. Graduado em Licenciatura em Geografia e Licenciatura em Ciências Sociais/Unisinos. E-mail: cristian-tisatto@hotmail.com.
}

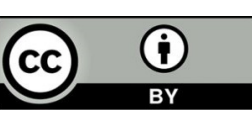


discussions and the construction of other alternatives - other paradigms for the construction of another possible world, capable of understanding social dynamics in a non-dualistic way, but in its uniqueness and complexity.

Keywords: Emancipation. Post-Modernity. Decolonial.

Recebido em 09/03/2020. Aceito em 19/10/2020

\section{Introdução}

A emancipação apresenta-se como uma categoria bastante cara para os estudos de sociologia. Tanto que se coloca, desde os estudos clássicos, como uma promessa histórica de transformação das realidades sociais - vislumbrada pelo progresso e avanço do mundo científico - apontando para as possibilidades da emancipação dos sujeitos a partir de movimentos históricos como o Iluminismo -também chamado de Século das Luzes.

As reflexões e teorias até então elaboradas sobre o conceito apresentam-se alicerçadas em contrapontos ou antagonismos concretos, a partir dos quais se busca contrapor e/ou efetivar o processo de emancipação. Afinal, quais os limites e os impedimentos para que se atinja a, talvez utópica, emancipação e liberdade humana? Para responder à questão, antes, é preciso refletir sobre o conceito. Revisitar significados e interpretações é importante na medida em que, por vezes, as palavras "[...] em determinadas épocas, [...] são focalizadas e afirmadas e outras silenciadas ou banidas. Isso também não é fortuito" (FRIGOTTO; CIAVATTA, 2003). Em relação à categoria emancipação, há questionamentos, reflexões e compreensões que variam de acordo com o tempo histórico-social. Seus usos e desusos configuram-se a partir dos contextos e desafios que nos mobilizam ou nos fragilizam, além de expressarem a nossa consciência sobre a necessidade ou não de processos emancipatórios. Daí a relevância do presente trabalho: propor uma reflexão sobre o conceito, na perspectiva de autores contemporâneos, realizando a:

vigilância crítica, buscando desvendar o sentido e o significado das palavras e dos conceitos, bem como perceber o que nomeiam ou escondem e que interesses articulam. Esta vigilância necessita ser redobrada em períodos históricos em que os conflitos e as disputas se acirram (FRIGOTTO; CIAVATTA; 2003, p. 46).

Convém destacar, a partir da vigilância crítica, a possível cooptação dos sentidos do conceito de emancipação. 0 mesmo pode ser aplicado em diferentes discursos, com origens e sob uma diversidade de interpretações. Inclusive, pode ser observado com veemência em ideias e teorias, pautados e fundamentados nos valores capitalistas, alinhados a perspectivas individualistas e com viés mercadológico - emancipar, restrito à ideia de ocupar a posição de opressão. Daí a relevância de debates que corroboram para que não sejam adotados discursos ingênuos, que possam nos conduzir à adesão de ideias de que a emancipação tem sentido único. Tanto que, com frequência, observa-se o emprego do conceito em discursos e interpretações de cunho mercantil, meritocrático e individualista - quando cada um é responsável pelo papel, isto é, pela posição que ocupa na estrutura social. 
Neste sentido, os estudos de sociologia são aportes teóricos que possibilitam a análise e o tratamento de diferentes categorias e perspectivas de análise, contribuindo para uma clareza conceitual que nos permite a reflexão sobre a temática e, no caso presente da categoria emancipação, compreender seu significado, assim como seus desafios e limitações.

Recorre-se então aos clássicos da sociologia, que corroboram no argumento de que a discussão sobre a emancipação não se trata de um fato novo ou recente, o que se observa, por exemplo, nas teorias clássicas, como a teoria marxista. Esta compreende o trabalho e a produção econômica no centro das discussões, e foi a partir dessa perspectiva que Marx propunha os ideais e as possibilidades de emancipação dos homens - romper com os processos de trabalho que alienam e não compreendem o trabalho como práxis humana. Já no caso weberiano, a discussão apresentava-se como uma possibilidade diante da realidade burocrática que permeava a ação social. Émile Durkheim, adepto de uma perspectiva estruturalista, analisava a sociedade a partir da relação entre indivíduo e coletividade, apontando os conceitos de solidariedade mecânica e orgânica como fundamentais para a compreensão das relações humanas. Tais teóricos, considerados de grande relevância na sociologia, contribuíram com interpretações e subsidiaram estudos posteriores, a exemplo destes que aqui propõe-se a abordar.

Embora a categoria emancipação é preocupação presente, observa-se a necessidade de sua ressignificação, colocando em discussão teóricos contemporâneos que a analisam a partir de diferentes perspectivas e constroem novas significações à categoria. Giddens, Santos e Bauman propõem-nos tal ressignificação, inclusive, alguns destes, embasando suas ideias em autores clássicos.

É relevante discutir o quanto se fazem necessárias as reflexões e atualizações sobre o tema em questão, o qual gera controvérsias em relação à sua legitimidade nos tempos atuais, haja vista a necessidade de atualizar ou ressignificar o uso da categoria emancipação.

O contexto atual apresenta-se com um conjunto de características e formas de organização social e individual - que se fundamenta em outros princípios de organização, diferente de outros tempos históricos. Na contemporaneidade, as relações sociais apresentam-se permeadas pelos conceitos de individualidade, fragmentação, e alicerçadas em lógicas de mercado e consumo. Como consequência, atores são afetados e modificados pelo curso das transformações observadas na história. Num período denominado por alguns autores de pós-modernidade (BAUMAN, 2001), decolonial (SANTOS, 2007), em que se combate um sentido único da história, a superação da hierarquia da produção do conhecimento e a divisão do mundo em norte e sul, respectivamente, cabe a avaliação das instituições e dos agentes, bem como seus interesses e anseios pela ideia de emancipação.

O presente artigo tem como proposta inicial a discussão da categoria emancipação a partir das novas relações sociais e do novo contexto histórico - denominado de Pós-Modernidade, a partir de Bauman (2001), ou decolonialidade, na perspectiva de Santos (2007) - buscando elementos que possibilitem a discussão do conceito, sua aplicação no atual período e sua ressignificação.

Desse modo, o ensaio organizar-se-á em três seções: na primeira delas, uma reflexão acerca do conceito na Sociologia, buscando autores que contribuem para elucidar tal ideia. A segunda buscará uma reflexão sobre as possibilidades de emancipação e as limitações do conceito na pós-modernidade. Por fim, apresentam-se as considerações finais.

O estudo foi realizado a partir de metodologia bibliográfica entre autores, que considera as realidades e as contradições, propondo, à luz da categoria emancipação, uma relação dialética a partir de três autores de referência na contemporaneidade: Anthony Giddens, Boaventura de 
Souza Santos e Zygmunt Bauman. Desse modo, desenvolver-se-ão, a partir de bibliografias, leituras e reflexões realizadas na atividade da Linha de Pesquisa I: "Sociedade, Economia e Emancipação", do Programa de Pós- Graduação em Ciências Sociais ${ }^{1}$, com base em atividade acadêmica de mesmo nome, desenvolvida no curso de Mestrado em Ciências Sociais da Universidade do Vale do Rio dos Sinos (Unisinos), ao qual o autor está vinculado.

\section{A emancipação enquanto categoria de análise na sociedade contemporânea}

Numa busca simples, recorrendo aos mecanismos de pesquisas de maior relevância no Brasil, tais como o servidor www.google.com, é possível encontrar 4.170 .000 resultados numa velocidade de 0,33 segundos, ou seja, pode-se concluir a imensidão de informações e de construções acerca do tema que se apresenta discutido sob diferentes lentes e enfoques, abrangendo diversas áreas do conhecimento e perspectivas de análise.

O novo tempo, marcado pela informação acelerada e atualizada, responsabiliza o agente sobre o seu modo de agir e pela constituição do devir a ser. 0 indivíduo torna-se protagonista e o responsável pela condução de suas relações, conquistas, méritos e fracassos. As instituições e o sentido de vida coletiva mostram-se fragilizados numa sociedade em que a estrutura não é imperativa. Santos (2007) propõe que, nas análises e diagnósticos da realidade,

não se deve ficar tão centrado na estrutura ou na ação e sim na rebeldia ou no conformismo. As estruturas pertencem à corrente fria, que é necessária, mas tem havido até agora uma maneira reducionista de ver esses obstáculos estruturais. (SANTOS, 2007, p. 61).

É, portanto, evidente a relação de agência e estrutura, na medida em que os agentes não estão condicionados exclusivamente a reproduzir a estrutura social - baseada num "consumir" - tampouco, devem restringir suas análises e processos de reflexão a uma ou outra forma de constituição de saberes, de informações e conhecimentos.

A partir de um mundo permeado pelo acesso facilitado à informação, renovam-se os valores e subsídios para novas configurações e relações sociais, que alguns sociólogos classificam como pós-modernidade ou modernidade líquida, conforme a teoria concebida pelo sociólogo polonês Zygmunt Bauman (2001), que alerta para um período de "aburguesamento dos despossuídos", em que se evidenciam:

Outros discursos frequentes para protestos semelhantes foram os do "aburguesamento" dos despossuídos (a substituição de "ser" por "ter" e a de "agir" por "ser" como os valores mais altos) e da "cultura de massas" (uma lesão cerebral coletiva causada pela "indústria cultural' plantando uma sede de entreteni-

\footnotetext{
${ }^{1}$ Programa de Pós-Graduação em Ciências Sociais - Universidade do Vale do Rio dos Sinos/RS. Conforme o PPG, a Linha de Pesquisa III - denominada Sociedade, Economia e Emancipação - direciona suas investigações às práticas e políticas sociais, considerando a presença da solidariedade e inquirindo seu sentido alternativo e emancipatório. Privilegia experiências associativas e cooperativas, sistemas de intercooperação, formas de empreendedorismo coletivo e iniciativas baseadas na reciprocidade, bem como movimentos, organizações do Terceiro Setor e políticas correspondentes. Investiga configurações sociais existentes no âmbito das relações de trabalho, de experiências democráticas, de comunidades e territórios, considerando suas potencialidades transformadoras a partir de suas respectivas epistemologias e saberes. Destaca as inovações geradoras de conhecimento e de soluções sustentáveis por via da participação cidadã e da cooperação entre atores. Disponível em: http://www.unisinos.br/mestrado-e-doutorado/ciencias-sociais/presencial/sao-leopoldo/ linhas-de-pesquisa. Acesso em: 03 set. 2020
} 
mento e diversão no lugar que - como diria Mathew Arnold - deveria ser ocupado pela "paixão pela doçura e pela luz e pela paixão de fazer com que estas triunfem. (BAUMAN, 2001, p. 26).

O trecho anteriormente exposto caracteriza o período em que se apontam novas configurações e características sociais, no qual o consumo e a coisificação dos humanos tornam-se claros e passam a ocupar um espaço central nas relações e prática sociais. Isso reforça e provoca-nos a refletir sobre a emergência da emancipação, sua legitimidade no mundo contemporâneo e o quanto se coloca como um anseio ou não destes atores que se movimentam com maior intensidade a partir de um processo racional e mais reflexivo, influenciado pelo avanço de acesso e produção do conhecimento, garantindo, assim, mais possibilidades de intervenções sobre as estruturas.

No capítulo da obra "Modernidade Líquida" (2001), Bauman debruça-se sobre o conceito emancipação, evidenciando alguns questionamentos que podem contribuir no esclarecimento dessa categoria social na atualidade. É unânime o desejo e interesse pela emancipação? Há grupos ou sociedades que não vislumbram, como fim, a emancipação? Afinal, seria ela uma benção ou maldição, como questiona Bauman? E, por fim, e de grande relevância, emancipar-se de quê? Qual seria o antagonista, o vilão que, de alguma forma, aprisiona-nos, amarra-nos e impede-nos de alcançarmos níveis satisfatórios e desejados de liberdade?

Quando se trata de tantas provocações e indaga-se em relação ao que foi apresentado, é fundamental discutir os caminhos das sociedades ocidentais, bem como os desafios emergentes que se apresentam, a fim de subsidiar discussões que, para alguns, resumem-se a potencialidades, e, para outros, em meras utopias que são discutidas desde a derrocada do socialismo, que se apresentava como um "outro mundo possível".

Em contraponto, o capitalismo, como sistema-mundo, expande-se, fomentando a autossatisfação, os sistemas abstratos, dando espaço e potencializando a universalização e globalização que se alastra e invade a vida cotidiana, formando subjetividades nos indivíduos e moldando comportamentos - o sistema-mundo invade o sistema privado, afetando processos psicossociais. Daí a tendência de se pensar a política de emancipação comprometida com a transformação de um sistema, que seja capaz de articular o conceito político-vida quando a política é incorporada às ações humanas, regendo a estruturação de relações, sem que necessariamente, priorize ou construa estruturas engessadas, desmobilizando as capacidades de agências de sujeitos e indivíduos.

o conceito de emancipação perpassa, portanto, o viés economicista, o qual é aqui tratado de maneira a ser aplicado em diferentes contextos, que vão desde a vida política, as dinâmicas econômicas, as perspectivas eurocêntricas e a construção do saber até as relações humanas, quando relacionadas a preconceitos, estigmas, padrões impostos por sociedades fundamentadas num ideal de consumo, o qual molda as identidades e favorece dinâmicas que mercantilizam relações humanas, colocando o mercado e o consumo como centrais nos processos de constituição dos indivíduos, entendendo o "consumo, aqui, não apenas no sentido mercadológico, mas também no sentido de consumo e venda de valores simbólicos”. (LEISTER, 2017, p. 2).

Trata-se do consumo e relações mercadológicas que ditam a construção de identidades, fazendo com que estas se apresentem de forma dilemática, tendo em vista o império do individualismo predominante nas relações e estabelecendo formas de vida mais solitárias e individualizadas. Vidas em que o mérito, a escolha, a decisão e o resultado das ações restringem a ação ou omissão individual, sem que desperte ou dinamize-se a partir de relações de solidariedade ou cooperação - voltadas ao coletivismo. 
O individualismo associado a mudanças nas concepções de tempo e espaço acaba por produzir outras noções destes. Numa sociedade projetada a partir da formação de consumidores, o tempo torna-se principal aliado na criação de necessidades e de novas formas de coerção social. Exemplo disso é o consumo que determina comportamentos a partir da criação de novas demandas, de modo a contribuir na construção da legitimidade dos sujeitos - "existo, sou reconhecido, se consumo" - e na inclusão/participação deste, de modo efetivo no mundo social, consolidando uma cultura baseada no imediato, no instantâneo e na relação indivíduo e individualização, além da satisfação e felicidade plena, contínua e sistemática.

No entanto, o entendimento de que as estruturas são deterministas na formação e constituição das relações humanas não se mostra unânime. O papel dos atores nos processos, em tempos de individualização crescente, é destacado, por exemplo, por Antony Giddens, que apresenta a tese da reflexividade, na qual analisa a sociedade a partir da habilidade, aptidão ou capacidade dos atores em desvendar ou fazer descobertas a partir de quatro características que recusam a ideia de que o comportamento humano é influenciado por ações externas; que as informações renovadas e constantes promovem reflexões, numa espécie de autoexame, que reconhece o uso da linguagem e o papel fundamental do indivíduo de refletir sobre condutas (FRIDMAN, 1999).

A partir da teoria de Giddens (1990:1995 apud FRIDMAN, 1999), a modernidade é alvo de processos constantes de reflexão, sendo realizados exames contínuos que vislumbram o acompanhamento das transformações numa ideia que o autor denomina "sistema peritos", que, como o próprio nome nos remete a pensar, propõe-se à revisão da ação e das práticas sociais, continuamente a partir do conjunto de informações que se renovam de acordo com as descobertas, provocando transformações na vida social que perpassam um ou outro segmento, abarcando e tornando-se elemento constitutivo das novas relações que vão processualmente se concretizando. Daí a necessidade de pensar meios e alternativas de emancipação a partir da contribuição destes e outros autores, como Santos (2007), que nos oferece uma categoria de Conhecimento Emancipatório, como a episteme e base para a consolidação de um processo emancipatório, que será tratado mais adiante.

No entanto, mesmo havendo processos de reflexão contínua, de novas descobertas, novos percursos e trajetos que vão constituindo a vida social, seria desejo da sociedade a transformação em prol de um viés emancipatório? Tal questionamento nos provoca a pensar e discutir a questão da emancipação, comparando-a com o ideal do "movimento" - característica da sociedade pós-moderna (na perspectiva de Bauman), ou decolonial (na perspectiva de Santos).

Ao mesmo tempo em que novas descobertas se fazem, e a partir delas, novas formas de sociabilidade e organização se constituem, é interesse das maiorias o "individualismo", aliado ao "comodismo" das mudanças graduais, num período de incertezas, em que ser livre para a libertação exigiria novos paradigmas na condução da vida social. Dito isso, ainda se pode questionar o exemplo que Bauman (2001) nos aponta: se os indivíduos estão concentrados na meritocracia individual, nos desafios e emergências que são próprios ao foro íntimo, à vida privada, quem seriam os agentes, os atores comprometidos com o pensar, refletir e desafiar o sistema-mundo, de modo a buscar novas possibilidades de efetivar grandes mudanças?

Bauman, no capítulo intitulado "Emancipação" do seu livro Modernidade Líquida (2001), utiliza-se de uma alegoria que facilita a compreensão do leitor a respeito da emancipação e da liberdade. $O$ autor utiliza a ideia de acampamento para explicar a noção de que, muito embora o acampamento seja um lugar aberto ao coletivo, compartilhado pelos diferentes atores, que pagam para se afixarem por um determinado período naquele território, ele não pertence a 
nenhum daqueles “pagantes”. A gestão não é responsabilidade daqueles que ali estão, mesmo que sejam afetados se alguma anomia for constatada. Nesses casos, o usuário poderá boicotar o clube/acampamento adotando outros espaços, mas se a crítica for a média do espaço, logo, todos incorporam novos hábitos, de modo a adaptar-se àquele ambiente. $\mathrm{O}$ exemplo ilustra a crítica de Bauman sobre a sociedade de consumo, que demonstra pouca preocupação com a coletividade ou com questões pertinentes ao grupo, buscando culpabilizar/responsabilizar outros pelas questões que emergem e precisam ser repensadas/consertadas, adotando uma política-vida que perpassa o modo de agir e isenta o indivíduo das responsabilidades coletivas. Ainda, Bauman (2001) preocupa-se em esclarecer o conceito de emancipação, que está relacionado ao movimento, à liberdade de poder agir sem obstáculos, afirmando que se libertar é, "literalmente libertar-se de algum tipo de grilhão que obstrui ou impede os movimento; começar a sentir-se livre para se mover ou agir". (BAUMAN, 2001 p. 23). Cabe, então, o questionamento que paira sobre tal conceito, que nos remete a uma reflexão quase que filosófica: agir e movimentar-se rumo a que lugar, a que destino, a que espaço-tempo?

Assim como Bauman (2001), Santos (2007) também se debruça sobre a categoria. No entanto, o segundo a compreende de maneira distinta. Em sua trajetória, especialmente nos últimos anos, Santos (2007) abdica da ideia e categoria pós-modernidade, apropriando-se do conceito de decolonialidade. $O$ autor adota o conceito e reflete sobre ele, utilizando-o como categoria de análise que explica e subsidia suas percepções e estudos sobre a sociedade contemporânea. Sua teoria remete-nos a questões clássicas, que pairam sobre estudos sociológicos desde os primórdios: o capitalismo - como fator de progresso e os processos de colonização que hoje se busca questionar -, o que se apresenta como tarefa complexa, tendo em vista que estamos inseridos num contexto marcado pela individualização e novas formas de alienação. Então, como pensar a emancipação do pensamento ou desnaturalizar formas de existência, amarrados à processos que nos limitam e restringem nosso olhar? Afinal, o capitalismo produz subjetividades, coloniza-nos nos saberes, nos fazeres e até mesmo nos prazeres. Somos, conforme Santos (2007), moldados; temos nossas mentes e formas de pensar aprisionadas pelas diferentes formas de dominação e alienação existentes e consolidadas. Moldam subjetividades, interesses e constroem unidades do saber, uma sociedade cada vez mais monocultural, estabelecendo formas de pensar, de fazer, de modo que tudo se resume a padrões, à reprodução da perspectiva colonial que perpassa as relações de saber, mas transforma as relações em outros e diferentes segmentos sociais.

Desse modo, cabe a reflexão: se há uma unidade do saber, um conhecimento único validado/ legitimado, formas únicas de construção da crítica, há espaço para a construção de um processo que nos emancipe, que fomente a construção de reflexões que vislumbrem a autonomia do indivíduo? Ou estamos, como propõe Santos (2007), fomentando um conhecimento regulatório, que visa manter a ordem, manter o que está, exatamente da maneira que está, reproduzindo cenas e cenários de desigualdades, injustiças e de reprodução da ordem vigente? Do contrário, pode-se pensar em possibilidades de promover reflexões sobre o colonialismo, indo de encontro ao que Santos (2007) propõe, categorizando como Conhecimento Emancipatório que elucida e revela as formas de dominação do pensamento, as estratégias de formação de subjetividades comprometidas com as hierarquias, com as opressões, que nos impedem de avançar, no sentido de expandir nossas mentes e libertá-las, de maneira a pensar de modo autônomo e independente? E o capitalismo, que se coloca a partir de uma filosofia, perpassa o viés economicista, ampliando-se, e "impõe-se" nas relações humanas, propõe formas de emancipação humana? Segundo os autores: 
A aceleração do capital destruiu e criou modos de vida. A carência de abertura de vias rápidas e amplas, verdadeiras artérias no corpo da urbe, a criação de instituições muradas, a proliferação de condomínios cercados, shoppings centers, vêm atender ao espírito do progresso e às suas necessidades devoradoras, marcando as cidades e as instituições educativas irreversivelmente. Sob o ímpeto de dar vazão à circulação e assegurar o seu controle, desentravando todos os obstáculos possíveis (ruelas, casas, acidentes naturais, topografias idiossincráticas, personas non gratas), as reformas urbanas contribuíram para o desaparecimento de modos de habitar e para a criação de formas de vida escolarizadas e confinadas. A crise que assola a educação nas cidades é incapaz de provocar o associativismo de uma ação política, caindo no vazio da escolha sem alternativa do indivíduo por si mesmo, com sua formação, nunca completa, e títulos para garantir chances em diversas oportunidades. (ZORDAN; SILVA, 2018).

A formação de subjetividades, o controle e a emancipação distanciam-se cada vez mais, enquanto ideal buscado pelas sociedades ocidentais, que exercem controle - controlam as relações, as cidades, colonizam o pensamento, silenciam saberes, privilegiam outros e pouco propõem uma terceira via, uma via alternativa, livre das amarras construídas pelos processos colonizadores que se reproduzem inclusive nas ciências, de modo que o conhecimento moderno, segundo Santos (2007), perverteu as possibilidades de emancipação, visto que reduziu conhecimentos, impondo lógicas oriundas de um certo "imperialismo" do conhecimento, uma divisão norte x sul, no qual o norte é o grande construtor, o grande colonizador. Para isso, faz-se necessário reinventar os conhecimentos, aprender o novo, sem desaprender o que já foi construído, sem classificar saberes.

Numa sociedade de consumo, em que o saber exerce lógica e relaciona-se diretamente com o poder, o consumo é imperativo à competição e à individualização, globalizando as relações e os saberes e propondo um diagnóstico capaz de transformar o mundo, em que a disputa e a tensão pairam entre o conformismo e a rebeldia, e a estrutura maior exerce pouca relevância, como alerta Santos (2007). No entanto, numa configuração social em que o individualismo, o saber global e a ciência a serviço do capital mostram-se imperativos nas relações humanas, o que nos move é a busca pela inquietação, pela promoção de "rebeldia", que nos movamos no sentido da mudança, não sem antes elaborar diagnósticos capazes de reduzir a desigualdade e a exclusão, tendo em vista que muitos atores sociais, de forma subjetiva, estão inseridos num contexto social, mas subordinados a outras lógicas, que os excluem e os diferenciam, marginalizando-os, obrigando-os a sair do contrato social, pela ausência da capacidade de participação numa sociedade marcada pelo consumo. Diante disso, aqueles que não possuem condições para fazê-lo, para se satisfazerem, para subsistirem e participar da vida coletiva acabam excluídos, haja vista que:

O capitalismo não para de lançar modelos subjetivos - tipologias que delimitam modos de ser, estar e transitar no mundo. Isso ocorre de tal maneira que a economia política se torna uma educação para a economia subjetiva, a ponto de não haver separação entre processos de subjetivação e a formação psicossocial. A capacidade de o capitalismo investir em formas de vida produz sujeitos em constante articulação dos fluxos econômicos, financeiros, culturais e sociais, os quais convergem na educação para a cidadania, ou seja, na educação para uma vida na cidade, ponto de ligação desses fluxos. (ZORDAN; SILVA, 2018).

Cultura que educa gostos, hábitos, crenças, seja pela educação formal nivelada por graus de ensino, a educação, enquanto conceito aplicado relativo ao preparo para a vida social e a compreensão da civilidade, constitui a instância própria para aparelhar a formação. (ZORDAN; SILVA, 2018). 
E naturaliza relações de consumo, que passa a ser o norte das relações humanas, formando uma economia:

Predadora, centrada no individual, pouco voltada ao coletivo e sem consideração com a natureza e suas fontes de matéria-prima. Trata-se de uma economia política que privilegia o consumo, a produção desenfreada e o mercado em detrimento do capital biopolítico cognitivo, o qual consideramos fator determinante na promoção de uma educação que mantenha a saúde individual, social, e a do planeta. (ZORDAN; SILVA, 2018).

Assim, fomenta a exploração do homem pelo homem, a primazia da propriedade privada e as novas formas de alienação. O sujeito não se aliena pela falta de acesso à informação, mas pela imensidão delas, que, numa velocidade intensa, chegam às casas e são compartilhadas, sem qualquer busca ou verificação - trata-se de um compartilhar informações, modos de ser, de pensar e agir, modelando comportamentos e reproduzindo um conhecimento muito mais regulador, do que propriamente emancipatório. Um conhecimento baseado no controle, na publicização de ideias e comportamentos que visa manter o status quo, a ordem social vigente. Daí o conceito e a busca pela efetivação da ideia de emancipação distanciam-se cada vez mais.

$\mathrm{O}$ acesso à informação e ao conhecimento acabam não respondendo às expectativas de progresso e de autonomia dos indivíduos. Pelo contrário, exercem a função de manutenção da organização social sem abertura de questionamentos ou reflexões. Daí a questão: emancipar-se do que? Do capitalismo e suas amarras, das subjetividades que o sistema impõe, das lógicas de consumo e prazer que norteiam a ação humana. Capitalismo capaz de formar uma nova racionalidade, a partir de uma Ecologia de Saberes, em que se aprende o novo sem marginalizar o antigo; em que se valoriza o Sul, sem esquecer das contribuições do norte. E então, pensar em possibilidades de uma via alternativa - uma terceira via - e romper com a dicotomia e a polarização do pensamento e do conhecimento, das formas de analisar, conceber e interpretar o mundo.

A sociedade contemporânea propõe a ruptura de dicotomias ou de visão binária: a disputa entre A e B - como se houvesse apenas duas lógicas, opostas umas às outras. E o questionamento que fortalece essa perspectiva de análise pode ser tratado de modo a responder e questionar: trabalha-se, enquanto sociedade, no sentido de regular as ações, adotando um conhecimento regulador ou busca-se a formulação de um conhecimento emancipatório, que não se concentre na individualização e autossatisfação, mas que seja capaz de identificar que subjetividades e que comportamentos vêm sendo provocados nas relações humanas?

Convém alertar que não se está aqui propondo uma revolução ou uma transformação radical e imediata. O que se pode propor é a intervenção, o repensar os espaços-tempos e as relações de modo que micro revoluções que se constroem no cotidiano possam ser fomentadas, discutidas e ampliem nossa perspectiva e nosso projeto enquanto sociedade humana que busca a libertação, com base na reflexividade, numa ecologia de saberes que considera os processos de aprender e reaprender, que não permita hierarquizações dos saberes e que se fundamente a partir de pensar as relações que se constituem nas diferentes esferas da vida social. E remeta-nos a questionar: o mote das discussões, o centro da existência humana, não seriam as relações? Não se coloca como relevante pensar como nós, humanos e sujeitos de relações, interagimos com o mundo e com outros? O que se discute e propõe aqui, conforme Santos (2007), não é "Criar um pensamento de vanguarda; o que estamos fazendo é compreender o mundo e transformá-lo junto com os movimentos e as associações que compartilham essa paixão conosco". (SANTOS, 2007, p. 60). 
A busca pelo movimento, proposto por Bauman (2001) quando conceitua emancipação, o aprender e reaprender de Santos (2007) e a reflexividade proposta por Giddens (1990:1995 apud FRIDMAN, 1999) são chaves, conceitos que nos permitem diagnósticos, embora de matrizes e conceitualmente diferentes, capazes de promover o movimento de pensar o mundo que temos, as utopias que buscamos alimentar e a própria ideia de emancipar, que se relaciona ao modo de existir ao qual, desde o nascimento, somos adaptados. Pensar um outro modo de vida, um modus operandi menos comprometido com a eficiência, com a hierarquia, com a economia, propõe superar a fragmentação do tempo e da vida. Propõe a utilização das tecnologias de modo que nos sirvam, e não ao contrário. Que sejam aliadas nos processos de crescimento e desenvolvimento humano, e não as responsáveis pelo aumento do desemprego estrutural. Que a flexibilidade que os novos espaços-tempos propostos sejam garantidores do não-comodismo, mas não de uma busca incansável por produção e indicadores de quantidade, medidos globalmente, mas reconhecidos localmente pelos seus avanços e singularidades.

\section{Desafios e possibilidades para a emancipação}

O que nos impede então, de pensar alternativas, ou, como proporia Santos (2007), um outro mundo possível? Que amarras comprometem e colonizam nosso pensamento de tal forma que promovemos uma educação que coloniza ideias, limita e aliena o pensamento, naturalizando desigualdades, opressões, nos fazendo aderir a uma lógica de consumir o conhecimento finalizado e acabado, aprendendo o que nos é determinado, sem qualquer espaço para novas criações ou espaços de reflexão que põe em xeque e questionem tais lógicas?

Conforme Carvalho (2009, p. 9), o "desafio de recriar a emancipação, no tempo presente de transição, é teórico, é político e é epistemológico”. Recriar, portanto, é o desejo de movimento, de reflexão e debate democrático, que alcance diferentes níveis e diferentes sujeitos; é político porque exige ação, práxis. Ideias desconectadas de ações não promovem transformação. Debates que se encerram em espaços de público restrito pouco colaboram com a perspectiva de questionamento das realidades, de promoção de ação coletiva, política e transformadora.

Para que haja movimento, transição, além de busca permanente, há que se organizar espaços coletivos de problematização das realidades, de conhecer e reconhecer o que nos aprisiona, que nos impede de avançar, de emancipar. Talvez esse seja um dos desafios da busca. Os indivíduos concentrados na busca pelo mérito individual, pela inclusão através do consumo e, portanto, trabalhando de forma alienada para geração de renda, de forma individualizada, não dispõem de tempo para problematizar a realidade em que vivem. Trabalham para consumir e, ao consumir, ampliam o desejo de ter mais. Quando ampliam tal desejo, necessitam dedicar-se mais ao trabalho.

O discurso da competição, de responsabilização individual pelos fracassos e sucessos mostra-se predominante numa sociedade cujas pautas e discussões têm influência da indústria cultural. Se cada um é responsável unicamente pelo que produziu durante sua existência, seu viver, é preciso que se busque a inserção naquilo que é padrão, que é comum a todos: o poder de consumir e, aí, ser reconhecido e legitimado como cidadão. Esse contexto, no entanto, fragmenta as relações sociais e prioriza o indivíduo em detrimento de coletivos que passam a ser projeto de ninguém.

Sem coletivo e espaços de reflexão e problematização das realidades, estabelecem-se vínculos e laços sociais fragilizados. Como consequência, sem pensar a realidade, não identificamos aquilo que nos amarra, nos aprisiona, tampouco reconhecemos a necessidade e a possibilidade 
da transformação, que não se dissocia da ação política comprometida com a práxis humana e no limite com a ação política. E é sob essa perspectiva que a epistemologia se apresenta, na medida em que se compreende a natureza, a origem dos saberes e fazeres, respondendo: como, por que e a partir de que se constroem determinados conhecimentos?

Conhecer a realidade de forma holística - proposta desafiadora - pode constituir-se como o início das relações coletivas que problematizam realidades e propõe intervenções através do diálogo, da solidariedade e da democracia - esta que deve nortear toda e qualquer discussão em que se aborde a emancipação de sujeitos, a fim de torná-los construtores da história a partir de uma democracia real, da tomada de consciência e da responsabilidade individual sobre ações coletivas -, resgatando o sentido da existência, do humano.

Um dos desafios para a construção do pensamento livre e da consciência sobre a realidade é, portanto, pensar outra racionalidade, o que pressupõe romper com a hegemonia do pensamento hierarquizado, legitimado, que naturaliza processos violentos de exclusão, de marginalização, expressos nas desigualdades sociais, por exemplo. Construir um pensamento livre e reconhecer as possibilidades do local e do global exige-nos a superação de verdades absolutas do fazer ciência, da construção do conhecimento que permeia teorias, métodos e epistemologias colonizadas, não oportunizando a reflexão para a emancipação, mas fomentando a reprodução. Conforme Santos:

[...] se explica que o conhecimento emancipatório pós-moderno tenha de enfrentar desde o início dois poderosos inimigos: os monopólios de interpretação e a renúncia à interpretação. O combate a ambos baseia-se na mesma estratégia: a proliferação de comunidades interpretativas (SANTOS, 2007, p. 95).

Emancipação não é mais que um conjunto de lutas processuais, sem fim definido. $O$ que a distingue de outros conjuntos de lutas é o sentido político da processualidade das lutas. Esse sentido é, para o campo social da emancipação, a ampliação e o aprofundamento das lutas democráticas em todos os espaços estruturais da prática social. (OLIVEIRA, 2008, p. 60).

A categoria então pressupõe luta permanente, reflexão constante e espaços coletivos que fomentem e problematizem realidades na construção de uma outra racionalidade e de uma democracia de alta intensidade, na perspectiva de Santos (2007). No entanto, tal processo é marcado por transição de paradigmas, buscando superação de exercícios de poder, de dominação, e construindo uma realidade compartilhada, que discuta alternativas, superando o modelo hegemônico vigente. É articular estratégias de superação das desigualdades, e há exemplos, iniciativas que vão ao encontro dessa proposta.

A Economia Solidária, os movimentos que discutem as cidades e suas dinâmicas, além de movimentos sociais tradicionais que dialogam sobre as problemáticas, do local ao global, mobilizam atores e comunidades. Esses coletivos organizam-se de modo a articular meios e criar instrumentos de emancipação capazes de discutir para além do que está posto. Constrói-se, portanto, uma outra racionalidade, a partir da superação da:

[...] ideia conservadora de que não há alternativa ao modo de vida imposto pelo hiper capitalismo em que vivemos cai por terra. Mostra-se que só não há alternativas porque o sistema político democrático foi levado a deixar de discutir as alternativas. (SANTOS, 2020, p. 06).

O hiper capitalismo, expresso a partir das relações neoliberais, pressupõe uma civilização fundada em princípios de opressão e dominação de uns sobre outros. No entanto, pensar a 
categoria emancipação supõe a construção de novas formas de sociabilidade, e isso passa pelo crivo de uma outra forma de construir o conhecimento. Exemplos de uma outra racionalidade requer a ruptura com a naturalização das diferenças que hierarquizam e excluem e, além disso, pautam-se numa “[... 'lógica da classificação social', assentada na naturalização das diferenças, distribuindo populações por categorias que naturalizam hierarquias: classificação racial; classificação sexual, dentre outras". (CARVALHO, 2009, p. 11).

Santos (2007) propõe uma ecologia dos saberes, no sentido de organizar e articular os saberes construídos com reflexão constante sobre a sua epistemologia, reconhecendo-se a prática social, o saber construído a serviço da construção de alternativas. Romper com lógicas de classificação que violam direitos, que excluem a partir do poder de consumo, que legitimam saberes em detrimento de outros, que segregam e tornam sujeitos invisíveis é um primeiro passo a superação das formas de opressão e dominação.

A ecologia dos saberes supõe a prática de reflexão alinhada a processos de ação que priorizem a busca pela consolidação da democracia nos diferentes espaços, assim como nas formas de viver e conviver. Emancipação pressupõe a luta, a busca pelas ideias que, mesmo que sob a acusação de pura utopia crítica, podem mobilizar indivíduos e coletivos a vislumbrar a transformação e a justiça social.

A existência da utopia mostra-se tão necessária quanto superar as exclusões e limitações impostas pelo capitalismo (SANTOS, 1999). O desejo de uma sociedade mais justa e de uma vida melhor para todos só é possível pensando uma outra racionalidade econômica, mesmo que nos pareça, num primeiro momento, uma ideia utópica. É importante referenciar que determinados eventos históricos, a exemplo da abolição dos sistemas escravagistas, um dia também foram considerados ideias utópicas. E o curso da história apontou-nos as possibilidades de concretização. Utopias mobilizam e fazem-nos buscar, articular e superar amarras. Nesse sentido, o diagnóstico - ter consciência da realidade - seguido da reflexão, é fundamental, para "reinventar a emancipação significa fortalecer esperanças por outros e melhores futuros, apontando alternativas concretas para reverter as diversas crises em andamento, as quais vêm se agravando nas últimas décadas". (PORTO, 2019 p. 4451).

Trata-se de um conceito que precisa ser reinventado, pois requer a criação de novos paradigmas e racionalidades para além do científico, e que impõe novas posições nas estruturas estáticas das Sociedades, em especial a instituições como o Estado.

Uma tal concepção da emancipação implica a criação de um novo senso comum político. A conversão da diferenciação do político no modo privilegiado de estruturação e diferenciação da prática social, tem como corolário a descentração relativo do Estado e do princípio do Estado [...]. (SANTOS, 1999, p. 239).

Assim, faz-se necessário todo esse movimento embasando e dando o subsídio para a esperança, da transformação - que é o motor da mudança, da busca, movida pela utopia e pelo anseio de renovação, de mudança:

Recuperar a esperança significa, neste contexto, alterar o estatuto da espera, tornando-a simultaneamente mais activa e mais ambígua. A utopia é, assim, o realismo desesperado de uma espera que se permite lutar pelo conteúdo da espera, não em geral mas no exacto lugar e tempo em que se encontra. A esperança não reside, pois, num princípio geral que providencia um futuro geral. Reside antes na possibilidade de criar campos de experimentação social onde 
seja possível resistir localmente às evidências da inevitabilidade, promovendo com êxito alternativas que parecem utópicas em todos os tempos e exceto naqueles em que ocorreram efetivamente. É este o realismo utópico que preside às iniciativas dos grupos oprimidos que, num mundo onde parece ter desaparecido a alternativa, vão construindo, um pouco por toda parte, alternativas locais que tornam possível uma vida digna e decente. (SANTOS, 1999, p. 36).

Ou seja, nos é oportunizado criar campos de experiências sociais, no micro, promover a revolução e a transformação com base nas utopias, desejos e na emergência das transformações - que modificam as relações sociais e econômicas, tendo em vista que a formulação de subjetividades - modos de pensar, agir e intervir no mundo - reinventam-se na mesma proporção que o capitalismo; enquanto sistema-mundo, renova-se, reinventa-se e ressignifica-se a partir das novas demandas, expandindo seus efeitos para além do econômico.

Emancipar envolve transformar; observar o constructo e suas contradições, de modo a diagnosticar a realidade; superar visões reducionistas sobre a vida humana e sobre as dominações impostas pelos próprios humanos, que exploram, controlam e constroem subjetividades uns nos outros; superar as visões universalizantes, construídas sob hierarquias (epistemologias do norte $\mathrm{x}$ sul) excludentes que limitam o pensamento, o conhecimento e, consequentemente, a ação política.

Tratar de emancipação requer a ação como instrumento de mudança e transformação de realidades. Os desafios postos a esse processo apresentam-se, conforme os autores, na emergência de superação da produção do conhecimento hierarquizada e legitimada, propondo-se um repensar sobre a epistemologia e a construção da ciência colonizada, uma ecologia de saberes - que propõe articulação e movimento caracterizado pela ação. Convém destacar a contribuição de Santos (1999) para discutir a construção de um outro senso comum. Giddens também contribui para pensar as limitações e possibilidades da busca pela emancipação a partir da ideia de reflexividade que propõe a construção de um coletivo, um interesse maior que nos mobilize e busque romper com individualismos e lógicas excludentes, apropriando-se de mecanismos de desencaixe.

Apropriar-se deles propõe uma superação daqueles mecanismos que buscam nos conduzir enquanto atores sociais a agir de forma inconsciente ou às consequências não desejadas ou pretendidas de nossas ações (ZAMBONI, 2012). Na perspectiva de Zamboni (2012), trata-se de romper com "práticas e preceitos preestabelecidos", deixando de naturalizar as relações e o mundo como se apresenta. Desse modo, "cabe à ciência social investigar a importância desses processos na reprodução de sistema e nos contextos ideológicos” (ZAMBONI, 2012).

Propor movimentos de transformação social provoca-nos a pensar sobre as permanências - o que deve ou não permanecer e a refletir, dialogar e construir conhecimentos para então fundamentar propostas, mobilizar indivíduos e depois coletivos capazes de pensar outro lugar para se viver, outra forma de existir e outras lógicas a seguir - primando pelo coletivo e pelas liberdades de ser, existir e conviver. Há muitas possibilidades para a emancipação emergir e concretizar-se como prática social. Em contrapartida, há, desafios que permanecem assombrando as lutas - que nos impedem de ver, de refletir, de articular com o coletivo e de nos mobilizar em prol de um destino a ser construído democraticamente e pensando uma outra racionalidade: sujeitos autônomos, de pensamento livre, operando a partir de racionalidades libertas do hiper capitalismo como ditador de relações humanas e a busca pelo bem-estar humano acima de qualquer outro valor, o que não significa mobilizar recursos, destruir habitats ou hierarquizar formas de vida. Pelo contrário, trata-se de pensar o bem-estar a curto, médio e longo prazo - do local 
ao global e de mover a sociedade em busca de um outro patamar de civilização, construindo e ressignificando a ideia de felicidade e progresso.

\section{Considerações finais}

Tratar do conceito de emancipação não é tarefa fácil, tendo em vista as inúmeras possibilidades de abordagem, flexibilidade e elasticidade do conceito. A partir dos novos tempos, da nova dinâmica e das diferentes relações sociais que se estabelecem, relacionar emancipação e consumo remete-nos a pensar o sistema social e econômico em que vivemos. E quando remetemos nossos pensamentos a diagnosticar a realidade, identifica-se que o sistema capitalista apresenta diferentes formas de mediar e modificar os processos sociais, ressignificando-se a cada crise que o sistema geralmente enfrenta.

O processo de mudança e de libertação dos paradigmas de consumo e dos princípios de mercado - que se alastram e regem também a dinâmica das relações humanas, formando subjetividades - pode se enquadrar nas teorias baseadas em mera utopia. O fato é que, independentemente de utopia ou esperança da transformação (esperança no sentido de ação), propõe-se adotar postura de reflexividade, de autoexame, conforme Giddens (1990:1995 apud FRIDMAN, 1999), e buscar formas de estabelecer um conhecimento emancipatório que nos liberte e nos faça movimentar em prol de uma ação de "rebeldia", ou seja, romper com dicotomias e criar um novo senso comum político, capaz de nos inquietar e nos movimentar na busca por novas formas de construção do pensamento, descolonizando mentes, comportamentos e promovendo rupturas em padrões, adotados sem qualquer processo de ressignificação.

Conforme propõem os autores base do presente estudo, o que se busca é o diagnóstico e a clareza para uma postura de reflexividade que nos auxilie a compreender as bases e origens que formam o pensamento ocidental e, de certa forma, contribuem para a formação. O processo de mudança pode ser considerado maroto, pois exige uma postura de reflexividade, todavia, antes de tudo, faz-se necessário compreender as bases e origens que formam o pensamento ocidental e, de certa forma, contribuem para formação de uma nova sociedade, com valores e princípios que se diferenciam de outros tempos históricos.

Diante do exposto, torna-se complexo pensar processos de emancipação, sem lembrarmos ou mencionarmos grandes revoluções do pensamento, como os movimentos que se efetivaram em ações, que modificaram práticas sociais. A partir do estudo sobre a categoria emancipação, identifica-se o consumo e o capital - como mecanismos de controle social, instrumentos que incutem valores, transformam comportamentos e investem em naturalizar as desigualdades, em reproduzir realidades sociais que corroboram para a continuidade de uma sociedade que preza o consumo, as relações de mercado e os princípios envolvidos nessa lógica, adentrando outros espaços e relações. O capitalismo não é somente um sistema econômico. E daí a necessidade de reinvenção de práticas econômicas e sociais, de modo que, hoje, o que nos condiciona e limita é o consumo e a transformação do mundo em capital - em mercado, onde tudo se compra, vende, troca e a preocupação central é o lucro e a competição. Como pensar processos de emancipação desvinculados de uma realidade que modifica valores e põe no centro das relações humanas o "ter", o "possuir"?

Giddens (1990:1995 apud FRIDMAN, 1999) alerta-nos sobre a necessidade de uma prática de autoexame, em que as sociedades refletem suas práticas e revisam pensamentos e concepções de mundo. A reflexividade garante possibilidade de construir um outro paradigma de pensamento, 
adotando uma posição ou postura, o que busca a descolonização das mentes, procurando compreender a dinâmica de uma sociedade que, cada vez mais, mostra-se fragmentada, individualista e competitiva, que tem seu ideal de emancipação baseado em seus anseios, desejos e angústias que limitam e os impedem de pensar e promover qualquer ruptura ou pequenas transformações.

Cabe ressaltar que não se propõem revoluções, como já mencionado. O que se propõe são ações individuais e mediadas por pequenos coletivos (com potencial de tornarem-se grandes), de modo a pensar e estruturar ações que visam romper ou diminuir demandas que acabam limitando as transformações sociais, criando novas subjetividades e colocando as lógicas excludentes, opressoras à margem, vislumbrando ações menos individuais e mais coletivas, promovendo espaços de trocas, compartilhamentos, de reflexão contínua e promovendo micro revoluções, estabelecendo novas racionalidades e rompendo com formas únicas de saber, com hierarquias que constroem pensamentos baseados numa lógica de exclusão e de hierarquização. É preciso pensar outras alternativas para além das dicotomias (capitalismo x socialismo, bom x ruim), e ainda, avançar no sentido de produzir uma outra política de vida e tornar a emancipação - um conceito tão claro e evidente - a ponto de tornar-se uma expectativa e um desejo de grande parte das sociedades globalizadas, incluindo saberes locais nas decisões, nas formas de vida e de existência dessas populações.

A mudança não se faz num dia apenas. Ela é como uma colcha de retalhos: a cada dia, novas ações, novos pensamentos e novas ideias até que modifiquem e transformem o tecido social e, o que era até então utopia, torna-se a esperança pautada no movimento e na ação política transformadora e coletiva. A reflexividade, a libertação da ditadura do consumo e do individualismo, bem como a construção da curiosidade, que nos inquieta e nos coloca em permanente busca pela desnaturalização do mundo como nos é apresentado, são movimentos que nos direcionam à emancipação.

\section{Referências}

BAUMAN, Zygmunt. Modernidade Líquida. Rio de janeiro: Jorge Zahar, 2001.

CARVALHO, Alba Maria Pinho de. Pensamento de Boaventura de Sousa Santos em foco: a reinvenção da emancipação em tempos contemporâneos. In: SEMINÁRIO DIÁLOGOS JURÍDICOS, 1., 18 ago. 2009, Universidade Federal do Ceará, Fortaleza, 2009. Anais eletrônicos [...]. Disponível em: tinyurl. com/14sw25vc . Acesso em: 27 dez. 2019. Acesso em: 23 dez. 2019.

FRIDMAN, Luis Carlos. Emancipação na teoria sociológica. In: ENCONTRO ANUAL DA ANPOCS, 23., 1999, Caxambu, MG. Anais eletrônicos [...]. Disponível em: tinyurl.com/4y3r8oqe . Acesso em: 27 dez. 2019.

FRIGOTTO, Gaudêncio; CIAVATTA, Maria. Educar o trabalhador cidadão produtivo ou o ser humano emancipado? Trabalho, educação e saúde, Rio de Janeiro, v.1, n.1, p. 45-60, 2003. Disponível em: https://www.scielo.br/scielo.php?pid=S1981-77462003000100005\&script=sci_abstract\&tlng=pt. Acesso em: 27 dez. 2019.

LEISTER, Rayssa. As relações humanas no turbocapitalismo: novas formas de alienação. 2017. Trabalho de conclusão de curso (Especialização em Gestão de Projetos Culturais) - Programa de PósGraduação em Gestão de Projetos Culturais, Universidade de São Paulo, São Paulo, 2017. Disponível em: tinyurl.com/3yant4b3 . Acesso em: 26 dez. 2019.

OLIVEIRA, Inês Barbosa. Boaventura e a educação. 2. ed. Belo Horizonte: Autêntica, 2008. 
PORTO, Marcelo Firpo de Souza. Crise das utopias e as quatro justiças: ecologias, epistemologias e emancipação social para reinventar a saúde coletiva. Ciência e Saúde Coletiva, Rio de Janeiro, v. 24, n.12, 25 nov. 2019. Disponível em: http://www.scielo.br/scielo.php?script=sci_arttext\&pid =S1413-81232019001204449. Acesso em: 27 dez. 2019.

SANTOS, Boaventura de Sousa. Pelas mãos de Alice: o social e o político na pós-modernidade. 7. ed. Porto: Afrontamento, 1999. Disponível em: http://josenorberto.com.br/SANTOS,\%20Boaventura\%20 de\%20Souza.\%20Pela\%20M\%C3\%A3o\%20de\%20Alice\%20o\%20social\%20e\%20o\%20pol\%C3\%ADtico\%20 na\%20p\%C3\%B3s-modernidade.pdf. Acesso em: 23 dez. 2019.

SANTOS, Boaventura de Sousa. Renovar a teoria crítica e reinventar a emancipação social. Tradução de Mouzar Benedito. São Paulo: Boitempo, 2007. Disponível em: tinyurl.com/4adxgagz .

ZAMBONI, Marcela. Infinito enquanto dure: a confiança nas relações amorosas à luz de Anthony Giddens. Estudos de Sociologia, Araraquara, v. 1. n. 17, 2013. Disponível em: https://periodicos.ufpe. br/revistas/revsocio/article/view/235232/28256

ZORDAN, Paola Basso Menna Barreto Gomes; SILVA, Marcio Tascheto da. Figuras da crise: cidades e educação. Revista Brasileira de Educação, Rio de Janeiro, v. 23, 03 dez. 2018. Disponível em: http:// www.scielo.br/scielo.php?script=sci_arttext\&pid=S1413-24782018000100603. Acesso em: 26 dez. 2019. 